\title{
DESKRIPSI DAN DOKUMENTASI PROSESI MAMBUEK PUWAU
}

\author{
Kiki Nofrijum ${ }^{1 *}$, Yerri Satria Putra ${ }^{2}$, Eka Meigalia ${ }^{3}$ \\ kikinofridum@gmail.com ${ }^{l *}$,yerri@hum.unand.ac.id²,ekameigalia@hum.unand.ac.id ${ }^{3}$ \\ Universitas Andalas Padang, Indonesia ${ }^{1,2,3}$
}

\begin{abstract}
ABSTRAK
Puwau (perahu tradisional) yang terdapat di Nagari Limo Koto masih digunakan sampai sekarang ini oleh masyarakatnya sebagai penunjang pekerjaannya. Termasuk juga dalam mempertahankan produksi pembuatan puwau atau yang dikenal dengan mambuek puwau. Tujuan dari penelitian ini adalah untuk mendokumentasikan dan mengklasifikasikan bentuk dan jenis folklor yang ada dalam prosesi mambuek puwau. Metode yang digunakan dalam penelitian ini menggunakan metode etnografi dan folklor yang diperoleh melalui teknik penelitian pendekatan etnografi, kemudian pra wawancara di tempat, wawancara di tempat dan teknik pengarsipan folklor. Pada prosesi mambuek puwau terdapat 7 prosesi yaitu 1) maniliak, 2) manobang, 3) mambuek karangko, 4) maelo/manuwunan puwau, 5) maondom, 6) mangombang puwau, dan 7) masang pongge.
\end{abstract}

Kata kunci: Mambuek Puwau; Perahu; Deskripsi; Folklor

\section{MAMBUEK PUWAU: DESCRIPTION AND DOCUMENTATION}

\begin{abstract}
Puwau (traditional boats) found in Nagari Limo Koto is still used today by the community to support their work. It includes maintaining the production of puwau or what is known as mambuek puwau. This research aims to document and classify the forms and types of folklore in the puwau mambuek procession. The method used in this research is ethnographic and folklore. Methods obtained through ethnographic approach research techniques, then pre-site interviews, on-site interviews, and folklore archiving techniques. In the puwau mambuek procession there are 7 processions, namely 1) maniliak, 2) manobang, 3) mambuek karangko, 4) maelo / manuwunan puwau, 5) maondom, 6) mangombang puwau, and 7) masang pongge.
\end{abstract}

Keywords: Mambuek Puwau; Kanoo; Description; Folklore

Jurnal Elektronik WACANA ETNIK - Vol 10 No 1 2021, (10-18) p ISSN 2089-8746, e ISSN 2302-7142

Submit: Februari 2021. Diterima Maret 2021. Publikasi: April 2021. 


\section{PENGANTAR}

Masyarakat Minangkabau telah mengenal perahu sampai pada tata cara produksi sejak dahulunya. Selain itu, masyarakat Minangkabau juga memiliki sebutan lain terhadap penamaan perahu yaitu biduak dan sampan. Sama dengan perahu pada umumnya, biduak dan sampan oleh masyarakat Minangkabau berfungsi sebagai sarana pemenuhan kebutuhan hidup sepeti mencari ikan, mencari sirtukil (pasir, batu dan kerikil) dan lain sebagainya. Dapat dikatakan bahwa aliran sungai yang ada di Minangkabau memiliki biduak atau sampan sebagai transportasi air mereka, seperti yang terdapat di Sijunjung.

Sijunjung merupakan sebuah wilayah kabupaten yang terletak di provinsi Sumatera Barat. Di Sijunjung, terdapat 8 aliran sungai yang mengalir yaitu Batang Palangki, Batang Ombilin, Batang Sukam, Batang Sumpur, Batang Kuantan, Batang Takung, Batang Sinamar, dan Batang Kulampi. Dengan banyaknya aliran sungai tentu masyarakat Sijunjung telah mengenal dan menggunakan perahu umumnya dan khususnya bagi masyarakat yang tinggal dekat sungai tersebut. Sampai sekarang perahu tradisional masih digunakan oleh masyarakat sebagai mata pencahariannya, termasuk di Nagari Limo Koto, Kecamatan Koto VII.

Kata puwau berasal dari kata perahu. Sampai sekarang puwau masih digunakan sebagai alat transportasi untuk penunjang masyarakatnya dalam memenuhi kebutuhan hidupnya. Akan tetapi penggunaan puwau tidak lagi seperti dahulu. Puwau kini hanya digunakan oleh masyarakat yang tinggal di tepian sungai saja. Kurangnya pemakaian puwau oleh masyarakat disebabkan oleh zaman yang semakin maju. Masyarakat sudah menggunakan transportasi darat sebagai penunjangnya dalam bekerja. Selain itu, adanya jembatan sebagai penghubung juga menyebabkan kurangnya pemakaian puwau. Puwau secara fungsinya masih sama dengan dahulunya.

Berbicara mengenai bentuk fisik, ada yang membuat unik dari puwau itu sendiri dengan perahu yang ada di tiap daerahnya. Secara fisik puwau di nagari Limo Koto ini secara keseluruhannya bewarna hitam dan terbuat dari sebatang pohon tanpa ada proses merakit ataupun penyambungan. Warna hitam di puwau bukan melalui proses mengecat dengan cat, akan tetapi warna hitamnya disebabkan oleh proses alami dari proses pembuatannya itu sendiri melalui teknik pembakaran.

Mambuek puwau adalah pembuatan perahu tradisional melalui tahapan- tahapan tertentu. Dalam proses Mambuek puwau itu sampai sekarang masih menjaga dan mewarisi cara pembuatan perahu secara tradisional. Selain itu, pada prosesi mambuek puwau juga terdapat semacam ritual dan kepercayaan rakyat yang masih dilakukan oleh tukang puwau (ahli perahu) dan masih melekat oleh masyarakat. Salah satunya tradisi Baimbauan.

Baimbauan ini merupakan sebuah tradisi yang dilakukan oleh tukang puwau ketika hendak menebang pohon yang akan menjadi bahan dasar utama pembuatan puwau. Tujuan Baimbauan dilakukan adalah untuk meminta izin dan menegaskan kembali kepada penghuni pohon (makhluk gaib) bahwa batang pohon tersebut benar-benar akan diambil dan akan ditebang untuk pengambilan bahan utama puwau. Tradisi ini masih bertahan sampai sekarang karena tukang puwau percaya bahwa batang pohon yang ada memiliki penghuninya masing- masing. Maka dari itu baimbauan dilakukan sebagai proses meminta izin kepada penghuni pohon. 
Dalam pelaksanaannya, sebelum batang akan ditebang, tukang puwau terlebih dahulu akan mematut batang pohon tersebut dengan sungguh-sungguh dengan berjalan mengelilingi batang pohon tersebut. Pada saat mengelilingi batang pohon tersebut, tukang puwau akan membacakan doa shalawat nabi dan setelah itu mengucapkan sebuah kalimat “Oi Jubilih nan manghuni batang koh, poilah lai! Batang koh ka den tobang lai”, sebelum batang tersebut akan ditebang oleh tukang puwau. Adapun tujuan penelitian terhadap objek kajian ini adalah untuk melakukan deskripsi secara jelas dan detil tentang prosesi Mambuek Puwau.

\section{KERANGKA TEORI DAN METODE}

Terdapat dua metode yang sangat cocok digunakan untuk penelitian ini, yaitu metode Etnografi dan metode Metode Folklor Mengenai metode Etnografi, Abdul Manan telah menjelaskan tentang metode Etnografi dalam bukunya Dimensi Metodologis Ilmu Sosial dan Humaniora. "Etnografi secara harfiah adalah suatu tulisan-tulisan atau laporan tentang suatu suku bangsa atau tentang budaya-budaya. Selain itu penelitian Etnografi ini dapat menghasilkan laporan yang begitu khas sehingga istilah Etnografi dapat digunakan sebagai acuan untuk sebuah metode penelitian yang menghasilkan laporan tersebut" (Manan dkk, 2015: 115).

Adapun langkah-langkah dalam metode Etnografi ini telah dituliskan juga oleh Abdul Manan yang merupakan rangkuman dari buku James Spradley. Ada 12 langkah dalam pengumpulan data yang harus dilakukan oleh peneliti. Langkah-langkah tersebut adalah menetapkan informan, mewawancarai informan, membuat catatan etnografi, mengajukan pertanyaan deskripsi, melakukan analisa wawancara, membuat analisa domain, mengajukan pertanyaan struktural, membuat analisa taksonomi, mengajukan pertanyaan kontras, membuat analisa komponen, menemukan tema-tema budaya, menulis suatu etnografi.

Peneliti juga menyusun dokumentasi dan klasifikasi secara jelas mengenai objek kajian yaitu prosesi mambuek puwau ini. Maka dari itu, metode Folklore menjadi pendekatan selanjutnya untuk mempermudah peneliti dalam mencapai objek penelitiannya. Ada tiga langkah yang digunakan untuk memperoleh data-data folklor tersebut yaitu pra penelitian di tempat, penelitian di tempat, dan cara pembuatan naskah folklor bagi pengarsipan (Danandjaja, 2002; 193-207): pra penelitian di tempat, penelitian di tempat, pembuatan naskah folklor bagi pengarsipan.

\section{HASIL DAN PEMBAHASAN}

\section{Maniliak (Menilik)}

Maniliak adalah proses awal yang dilakukan dalam pembuatan puwau. Dalam KBBI V (Kamus Besar Bahasa Indonesia), kata maniliak disebut dengan menilik. Menilik berarti proses mengamat-amati dan melihat dengan sungguh- sungguh. Maka dari itu dapat disimpulkan, maniliek dalam proses ini ialah proses mengamati ataupun melihat batang pohon yang dilakukan oleh tukang puwau untuk pencarian bahan dasar pembuatan puwau.

Dalam proses awal ini, yang dilakukan adalah pencarian batang pohon yang akan menjadi bahan utama dalam pembuatan puwau. Proses ini akan dilakukan oleh tukang puwau, karena dialah yang terpenting dan yang dapat 
melakukan proses ini. Oleh sebab itu, tukang puwau yang nantinya akan mematut atau mengamati pohon mana yang akan dijadikan sebagai bahan utama puwau nantinya.

Batang pohon yang akan menjadi bahan utama pembuatan puwau ini terdapat 3 jenis batang pohon yang hanya dapat dijadikan sebagai bahan utama. Batang pohon tersebut adalah batang Cubodak Utan (artocarpus integer), batang Tampunek (Artocarpus Rigidus) dan batang Tarok (Artocarpus Elasticus). Menurut tukang puwau sendiri, batang pohon tersebutlah yang sesuai dijadikan sebagai bahan utama karena batang pohon tersebut ukurannya cukup besar dan dapat menyerap air. Biasanya, batang pohon ini hanya berada di perbukitan dan hutan saja. Jadi, proses Maniliak dilakukan di perbukitan atau hutan dimana batang pohon tersebut berada.

Dalam proses maniliak ini, ada dua peralatan yang sangat penting dibawa oleh tukang puwau, yaitu kapak dan paku. Tukang puwau akan mengamati dan mematut batang pohon mana yang akan dijadikan untuk bahan utama tersebut, hal ini berfungsi untuk mencari pohon mana saja yang layak untuk dipilih. Akan tetapi, layak dipilih belum tentu pula pohon itu sudah pasti menjadi bahan utama nantinya. Ketika Tukang puwau telah menemukan beberapa batang pohon yang anggap layak untuk dipilih, selanjutnya Tukang puwau akan menancapkan paku ataupun kapak di tiap-tiap pohonnya.

\section{Manobang (Menebang)}

Setelah proses maniliak batang dilakukan, selanjutnya tukang puwau akan kembali lagi ke perbukitan atau hutan tempat ia Maniliak sebelumnya. Dengan tahap selanjutnya yaitu proses penebangan, setelah 2-3 hari lamanya melakukan proses maniliak batang tersebut.

Meskipun dalam perencanaannya, tukang puwau akan masuk pada tahap penebengan sebagaimana mestinya, akan tetapi hal itu belumlah dapat dipastikan apakah tukang puwau akan benar-benar dapat melakukan penebangan. Hal ini masih tergantung pada prosesi Maniliak sebelumnya. Menurut Naswan selaku tukang puwau, proses penebangan masih tergantung pada sipenghuni pohon tersebut apakah telah mengizinkan atau tidaknya untuk ditebang. Jika dari salah satu pohon yang telah ditilik sebelumnya mendapatkan izin, maka pada hari itu proses penebangan dapat dilakukan, dan jika tidak, artinya perencanaan penebangan bisa gagal dan akan dilanjutkan pada proses Maniliak kembali ke perbukitan lain ataupun hutan lain.

Jika proses penebangan dapat dilakukan, maka pada hari itu penebangan langsung dilaksanakan. Sebelum penebangan tersebut dilakukan, terlebih dahulu tukang puwau akan melaksanakan sebuah prosesi yang disebut dengan Baimbauan. Tradisi baimbauan lebih pada pengulangan dan penegasan kembali kepada penghuni pohon bahwasanya batang pohon tersebut akan ditebang.

Dalam pelaksanaan penebangan batang pohon, istilah penebangan yang dilakukan disebut dengan batakuak batimba. Batakuak batimba merupakan sebuah istilah untuk teknik penebangan batang pohon dengan cara batakuak (menebang bagian bawah di pangkal pohon) dan batimba (menebang di belakang bagian atas pangkal pohon). Batakuak batimba dilakukan agar mempermudah tukang puwau mengarahkan posisi jatuh batang pohon. 
Selain itu, ada perbedaan dalam cara penebangan batang pohon yaitu batang tarok. Meski tetap dengan cara batakuak batimba, akan tetapi batang tarok memiliki cara tersendiri dalam proses penebangannya. Jika pada batang cubodak utan dan batang tampunek menebang dengan langsung ke pangkal pohon, maka pada batang tarok dalam penebangannya dilakukan di bagian tengah pohon. Hal itu disebabkan karena batang tarok memiliki baniagh. Baniagh merupakan urat pohon yang sampai ke pangkal luar pohon yang hampir setinggi manusia.

Jadi dalam pengerjaannya pada batang tarok, tukang puwau akan membuat palanta sesuai tinggi yang dibutuhkan agar tukang puwau dapat dengan mudah menjangkau bagian yang akan ditebang. Terlebih dahulu tukang puwau mempersiapkan tukie (tempat berdiri), lalu mengikatnya dengan akar sehingga menjadi palanta untuk tukang puwau berdiri. Palanta tersebut langsung dipasangkan melekat dengan batang tarok tersebut dan langsung melakukan proses penebangan dengan cara batakuak batimba.

Apabila batang pohon telah ditebang, selanjutnya tukang puwau akan langsung mengukur batang pohon tersebut. Pengukuran batang pohon ini biasa disebut dengan mandopo. Mandopo merupakan teknik pengukuran panjang pohon dengan cara membentangkan kedua tangan. Untuk membuat kerangka nantinya, maka panjang batang pohon yang akan diperlukan Tukang puwau berkisar 5-6 Dopo (5-6 kali bentangan kedua tangan). Setelah itu, batang pohon langsung Dikabuang (dipotong) dan Manggirik (membersihkan).

\section{Mambuek Karangko (Membuat Kerangka)}

Ketika prosesi manobang telah dilakukan, maka tahap selanjutnya akan masuk pada proses mambuek karangko. Mambuek karangko adalah proses pembuatan kerangka dasar puwau. Dalam pelaksanaanya, mambuek karangko ini dapat dikerjakan 3-4 hari lamanya.

Dalam mambuek karangko ini, proses pengerjaannya masih dengan cara tradisional. Hal ini ditunjukkan dengan masih dipergunakannya alat-alat tradisional untuk pembuatannya. Peralatan wajib yang digunakan itu adalah kapak beliong, benang, pahat, dan kapak. Ada beberapa tahap yang dilakukan oleh tukang puwau dalam proses ini untuk menjadi sebuah kerangka puwau. Tahap itu antara lain mananggam, mandado, mambonang, buek sumu-sumu, mangupak sumu-sumu, buang pipi, manitia tulang pungguang, dan manggiliang.

Mananggam/ditanggam adalah proses awal dalam pembuatan puwau yang dalam pengerjaannya tukang puwau akan membuka kulit dari batang pohon tersebut. Dalam pelaksanaannya, tukang puwau tidak akan membuka kulit secara keseluruhan langsung, akan tetapi tukang puwau mengiris kulit kayu tersebut dengan cara mengirisnya perjarak. Jadi, membuka kulit dilakukan sedikit demi sedikit, seperti mencincang kulit kayu dengan merata agar nantinya tukang puwau dengan mudah membuka kulit tersebut secara keseluruhan. Hal ini dilakukan agar dalam pengerjaannya lebih efisien dan agar tidak merusak batang tersebut.

Setelah semua kulit kayu terkupas semuanya, tahap selanjutnya yang akan dilakukan adalah mandado. Berasal dari kata dasar dado (dada), jadi istilah mandado dalam tahap ini adalah proses mendatarkan batang yang akan menjadi bagian atas kerangka puwau. Tukang puwau dalam hal ini akan mendatarkan batang tersebut mulai dari pangkal sampai ujung untuk membentuk bagian atasnya saja dengan menggunakan kapak beliong sebagai peralatan utamanya. 
Setelah melakukan mandado, tahap selanjutnya yaitu mambonang. Mambonang merupakan teknik pengkuran untuk membuat bibir puwau. Untuk melakukan pengukuran tersebut, tukang puwau akan menggunakan benang sebagai media pengukurnya. Dalam pelaksanaannya, tukang puwau menggunakan 2 buah benang yang panjang. Lalu benang dibentangkan di bagian atas puwau yang telah didatarkan sebelumnya pada tahap mandado tadi. Benang dibentangkan dari pangkal sampai ujung di bagian sisi yang datar tersebut. Hal tersebut dilakukan tukang puwau untuk membentuk bibir puwau.

Apabila mambonang telah dikerjakan, selanjutnya yang akan dilakukan adalah buek sumu-sumu. Buek sumusити merupakan sebuah proses melubangi bagian atas puwau. Dalam pengerjaannya, pahat dan kapak beliong menjadi bahan yang sangat penting dalam pengerjaan ini karena bagian atas puwau akan dilubangi yang mana akan menggunakan peralatan tersebut.

Pada tahap ini, terlebih dahulu tukang puwau akan membuat lubang- lubang kecil dengan berjarak sampai batas bibir puwau yang telah dibuat sebelumnya pada saat mambonang. Apabila telah terbuat lubang-lubang tersebut, kemudian lubang tersebut dikupas keseluruhan dengan kapak beliong. Selanjutnya tukang puwau akan membuat lubang-lubang kecil lagi lalu mengupas kembali dengan kapak beliong sampai lubangnya benar-benar dalam dan besar sesuai yang telah diukur oleh tukang puwau sehingga sudah membentuk bibir puwau dengan jelas.

Buang pipi merupakan lanjutan dari mambonang tersebut. Dalam hal ini, buang pipi adalah proses mengupas atau membersihkan bagian pipi puwau yang terletak antara bibir puwau dengan bagian bawah puwau. Apabila mambonang telah dilakukan dan telah mendapatkan ukuran yang tepat, maka selanjutnya tukang puwau akan langsung masuk dalam pengerjaan buang pipi tersebut. Tukang puwau akan mengupas ataupun mengikis dengan perlahan bagian pipi puwau tersebut. Hal ini berfungsi untuk menetapkan ukuran ketebalan dari puwau tersebut.

Apabila proses buang pipi telah selesai dilakukan, selanjutnya TUKANG puwau akan memeriksa bagian bawah puwau atau punggung puwau. Proses ini dinamakan dengan istilah manitia tulang pungguang. Manitia tulang pungguang adalah proses pembersihan dan pemolesan bentuk punggung puwau. Manggiliang merupakan proses akhir mambuek karangko puwau. Proses ini merupakan penyelesaian dengan membersihkan seluruh bagian kerangka puwau. Dalam pelaksanaan manggiliang ini, tukang puwau akan memeriksa bagian puwau yang masih kurang tepat dari segi bentuk dan ukurannya, lalu setelah itu TUKANG puwau akan membersihkan ataupun memperbaiki bagian puwau yang bermasalah tersebut. 


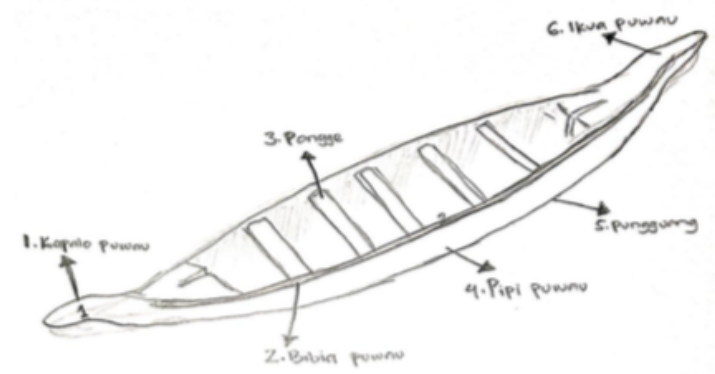

GAMBAR 1. Sketsa Puwau

\section{Manuwunan / Maelo Puwau}

Setelah mambuek karangko dan telah terbentuk dasar puwau, selanjutnya batang pohon atau dasar puwau tersebut akan diturunkan atau dibawa ke tepian sungai. Proses ini biasa disebut dengan manuwunan (menurunkan) atau maelo (menarik) puwau.

Manuwunan dan maelo memiliki arti yang berbeda satu sama lainnya. Manuwunan adalah proses menurunkan puwau ke tepian sungai yang apabila batang pohon tersebut ditebang di perbukitan. Sebaliknya, maelo adalah proses menarik puwau ke tepian sungai dengan tenaga manusia atau juga dengan kerbau yang apabila batang pohon ditebang di hutan. Perbedaan dalam bentuk kerjanya itu disebabkan oleh medan jalan yang jelas berbeda antara hutan dan perbukitan.

\section{Maondom (Merendam)}

Apabila puwau tersebut telah tiba di tepian sungai, maka proses selanjutnya akan masuk pada proses maondom. Maondom barasal dari kata merendam. Dalam hal ini, maondom puwau merupakan proses perendeman puwau. Jadi, batang pohon yang telah menjadi kerangka awal tadi, maka selanjutnya puwau direndam di dalam sungai.

Proses perendaman dilakukan dengan cara puwau diikat di tepian agar tidak lepas dan puwau yang telah masuk dalam air dibenamkan dekat tepian tersebut dan lalu Puwau diisi dengan batu-batu untuk memberatkannya agar tidak mudah mengapung. Proses maondom puwau memang hanya sekedar tahap perendaman dengan membenamkan puwau saja ke tepian sungai. Akan tetapi proses ini membutuhkan waktu yang cukup lama untuk menunggu proses perendaman tersebut.

Menurut tukang puwau, proses ini membutuhkan waktu 7-15 hari lamanya. Menurutnya hal ini dilakukan agar puwau itu dapat menyerap air. Resapan air dalam puwau tersebut berfungsi agar Puwau memiliki tingkat kelembapan yang tinggi. Hal ini dilakukan, karena fungsinya itu terletak pada kelembapan Puwau tersebut.

6. Mangombang Puwau (Mengembangkan Puwau)

Setelah 7-15 hari lamanya puwau itu direndam, maka puwau tersebut akan diangkat atau dikeluarkan dari perendaman tersebut. Pengangkatan puwau dilakukan dengan cara menarik tali pengikatnya secara bersamaan menuju 
tepian. Apabila puwau sudah terangkat keluar ke tempat sebelumnya, puwau akan dibiarkan dalam keadaan basah tanpa membersihkannya sekalipun. Selanjutnya, barulah masuk pada proses mangombang puwau.

Mangombang puwau merupakan proses pengembangan puwau yang dilakukan dengan cara dibakar. Proses mangombang puwau ini membutuhkan kecermatan dan ketelitian Tukang puwau dalam proses pembakaran agar puwau yang dibakar tidak dilahap api nantinya.

Untuk masuk pada proses ini, sebelumnya tukang puwau akan mempersiapkan terlebih dahulu beberapa peralatan wajib guna mempermudah nantinya untuk proses mangombang puwau. Peralatan yang disiapkan itu adalah sopik-sopik, lepoh, daun kambie, galang, kulik kayu, akar, dan lain-lain. Selanjutnya, barulah masuk pada proses mangombang puwau.

\section{Mamasang Pongge (Memasang Pongge)}

Proses pengembangan ini dilakukan oleh tukang puwau dan biasanya dibantu oleh anak buahnya. Namun tetaplah tukang puwau yang akan memegang kendali. Sebab, dalam proses ini tukang puwau memang terfokus pada ketetapan dan kesesuaian dalam proses mangombang puwau ini seperti melihat besar kecilnya api pembakaran, ketebalan puwau, dan sampai pada pengembangan puwau. Setelah dilakukannya mangombang puwau dan telah terbentuk sebuah puwau, maka tahap selanjutnya adalah masang pongge. Masang pongge adalah proses pemasangan tempat duduk perahu dari balok kayu.

Dalam pelaksanaannya, tukang puwau sebelumnya telah mempersiapkan pongge yang akan dipasang sekitar 7-10 buah tergantung besar dan panjang puwau-nya. Selanjutnya, pongge yang terbuat dari kayu tersebut di ukur sesuai lebar puwau. Jika telah diukur, maka pongge langsung dipasang dengan cara teknik pasak lalu memasukkan dan disesuaikan pada ujung lebar puwau.

Masang pongge merupakan proses akhir dalam prosesi mambuek puwau ini. Pongge berfungsi sebagai tempat duduk penumpang. Selain itu, pongge juga berfungsi sebagai penahan kembang puwau agar lebar puwau tetap terjaga dan bibir puwau tidak menarik ke dalam dengan sendirinya. Apabila masang pongge telah selesai dikerjakan, maka telah dapat dikatakan bahwa proses mambuek puwau telah selesai. Puwau siap di tes dan digunakan oleh pemilik puwau.

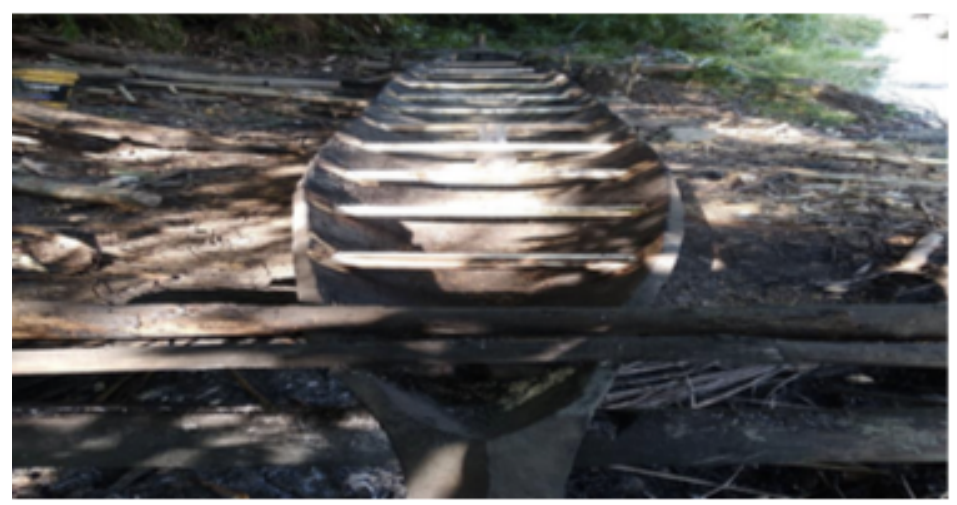

GAMBAR 2. Puwau 


\section{PENUTUP}

Prosesi mambuek puwau di Nagari Limo Koto, Kecamatan Koto VII, Kabupaten Sijunjung merupakan salah satu folklor yang terdapat di Minangkabau. Oleh karena itu, penelitian ini pertama kali dikerjakan dan sangat penting untuk dilakukan, karena prosesi mambuek puwau ini merupakan identitas masyarakat nagari Limo Koto. Selain itu, penelitian ini juga menjadi arsip dan penyelamatan terhadap aset kebudayaan dalam bentuk pendokumentasian agar generasi muda dapat dengan mudah mengetahui aset kebudayaan yang sangat penting ini bagi masyarakat Limo Koto khususnya dan masyarakat Minangkabau umumnya.

Tradisi mambuek puwau masih dapat dikaji dengan bidang kebudayaan lainnya karena tradisi mambuek puwau ini belum banyak dilakukan penelitiannya. Misalkan saja mengkaji bagaimana pemikiran orang terdahulu tentang bagaimana mengembangkan perahu dengan cara dipanggang dan tidak dilahap oleh api, dan masih banyak celah kajian lainnya.

\section{REFERENSI}

Putra, Y Thendra Bima. 2019. Terancam Punah; Sisa-sisa Puwau Di Tanjung Ampalu. Padang: Reportase Koran Harian Khazanah.

Diradjo, Ibrahim Dt. Sanggoeno. 2016. Tambo Alam Minangkabau; Tatanan Adat Warisan Nenek Moyang Orang Minang. Bukittinggi: Kristal Multimedia.

Ratna, Nyoman Kutha. 2016. Metodologi Penelitian; Kajian Budaya dan Ilmu Sosial Humaniora Pada Umumnya. Yogyakarta: Pustaka Pelajar.

Kurnia, Febby Eka. 2015. "Mitos Tentang Batu-batu Di Luhak Nan Tuo". Skripsi. Universitas Andalas.

Manan, Abdul, dkk. 2015. Dimensi Metodologis Ilmu Sosial Dan Humaniora 3. Banda Aceh: Lhee Sagoe Press

Pratama, Fandi. 2015. "Prosesi Penyelenggaraan Jenazah Panghulu Di Nagari Sungai Patai Kabupaten Tanah Datar (Dokumentasi Dan Deskripsi)". Skripsi. Universitas Andalas.

Setia, Nengsi Canber. 2014. "Tradisi Balimau Paga Di Kenagarian Koto Nan Duo IV Koto Hilie, Kecamatan Batang Kapas, Kabupaten Pesisir Selatan". Skripsi. Universitas Andalas.

Suardi, Akil. 2012. "Tradisi Mambayia Kaua Dan Pasambahannya Di Nagari Pulasan, Kecamatan Tanjung Gadang, Kabupaten Sijunjung". Skripsi. Universitas Andalas.

Jastro, Elymart. 2010. "Kajian Perahu Tradisional Nusantara Di Museum Bahari Jakarta Utara (Proses Produksi Pesan Tentang Teknologi Perahu)". Skripsi. Universitas Indonesia.

Asnan, Gusti. 2007. Dunia Maritim Pantai Barat Sumatra. Yogyakarta: Ombak.

Danandjaja, James. 1984. Folklor Indonesia : Ilmu gosip, Dongeng dan lain-lain. Jakarta: Pustaka Utama Grafiti.

Saifudin, Usep. 2019. "Tentang Profil Nagari; Asal-usul Nagari Limo Koto" dalam http://limokoto.sideka.id/ diakses pada tanggal 09/03/2020. 